\title{
City CIS in shaping the role of urban cultural characteristics
}

\author{
Jingsen Zhang, Xu Chen \\ School of Art and Design, Guilin University of Electronic Technology, Guilin 541004, China \\ chenxu1968@gmail.com
}

Keywords: CIS , Culture of City, Feature.

\begin{abstract}
The importance of urban culture have unique cultural connotation and unique charm, reflect regional, ethnic and cultural characteristics; changes reflect the times; in the spirit of long-term impact on everyone living in this environment. Connotation of this culture requires a certain visual language to reflect, (corporate image recognition system) introducing CIS to the overall image of the city as a starting point, the use of visual language disseminate city information, and to meet the public's spiritual and material needs, establish a city the overall image, to shape the characteristics of urban culture play a very key role.
\end{abstract}

\section{Introduction}

Huge cities as the carrier material, loaded with vital functions of people's social, cultural, productive activities. It uses concrete images to people with a living space environment and provide the required place, space, facilities, information and resources for a variety of social activities. However, the full significance of urbanization not only in that city as a business center Collection of production and trade, but also that "it makes the city as the rapid spread of information, dissemination of knowledge and culture that people feel for each other on the stage." Pursue the process of urbanization should be based on human nature and human society as the starting point and the return point, constitutes a city of culture.

Urban culture is the most important thing is to have a unique culture, to highlight the difference between this city and another city. Human pursuit of survival way of art and culture, is the pursuit of perfection in the process itself, but also promote the development of the process of social civilization. Connotation of urban culture is the need for a certain visual language to reflect, reflect people's minds, to reflect changes of the times, and in the spirit of long-term impact on everyone living in this environment. The manifestation of this urban culture is to be in the city itself the overall image as a starting point, reflecting the unique geography, culture, and only correctly establish urban concept, image, behavior, in order to ensure that urban management department rational development of urban construction, urban truly become a social, economic and cultural activity center. Content That city CIS, CIS system is the use of the theory, methods for the city's infrastructure design, logo image maintenance, building community culture, as well as a comprehensive economic, scientific, cultural and other aspects of literacy - the CIS Theory To city image design to the overall image of the city as a starting point, the use of visual language disseminate city information, and to meet the public's spiritual and material needs, establish the overall image of the city, beautify and improve the environment and facilities, to shape the characteristics of urban culture play a very crucial role.

\section{CIS connotation of urban design}

CIS (Corporate Identity System) is intended corporate image recognition system, CIS theory to create a good corporate image and consumer goods companies seek coexistence of shared economic and ecological relations for the purpose of the enterprise from the complex internal and external relations in order to sort out, set business ideas, business properties, business services, corporate reputation and corporate image in one, the establishment of a common and simple visual image, the overall image of an enterprise, it has a distinct personality characteristics. 
CIS includes the concept of identification MI (Management Identity), is the core and foundation of the CIS, is corporate culture, the spirit of lies, including philosophy, management creed, spiritual slogans, corporate personality, etc; behavior identification BI (Behavior Identity), is in order to reflect the spirit of enterprise, management strategy, improve corporate culture, expand their enterprises carried out a series of activities, including internal staff education, industrial environment, welfare, equipment management, anti-pollution measures, and external market research, public relations, public activities; visual recognition VI (vision Identity) is organized to carry out carefully planned, designed with a modern aesthetic elements of visual identity - logo, standard word, standard color, slogans, symbolic patterns, marketing, report, etc., through a variety of media way system transmitted to the relevant organizations and individuals, with a unique personality, unconventional deepen enterprise visual image impression in people's minds.

Urban design visual identity system CIS system that is urban, urban and interact with the public, a way to contact. Urban internal and external public awareness and recognition of urban abstraction. Simply put, is a contemporary CIS strategic theory mainly to urban development strategy as the goal, the overall image of the city as a starting point, the use of visual language disseminate city information, and establish a corporate identity different system for the city's image, the three major corporate image recognition system that is MI, BI, VI directly grafted to the city recognition system, establish a distinctive image of the city, the city is conducive to the economic and cultural development and continuation.

\section{The basic elements of urban design CIS design}

\subsection{Urban Design logo}

CI logo design is the basic element of design should be distinguishable, easy memory function. Image of the city must be identifiable with personality, this distinctive character recognition is to rely on the various elements of urban design to promote the recognition system set up, which is one of the basic elements of the logo design is very important. City logo to serve the public, must be easily understood by the public, to identify, reflect regional, cultural, times, only the combination of all three to fully express the context of the city, reflecting the significance of the concept of time and space, and the performance of the city's cultural connotation distinct personality. Design is to give people an elegant living environment, in this environment people can get physical and mental enjoyment.

\subsection{Urban and image-oriented facility design}

City guide culture environment construction planning affecting urban image of the design, its cultural content is very large, in the hustle and bustle of modern urban life, the absence of visual symbols is unthinkable. Design of Urban Identification System should follow the guidance of the city's nature, size, direction of development and economic capacity of the general plans to meet the physical needs of people on this basis, security needs, psychological needs, self-improvement needs and other needs of life, to achieve the design the concern for the natural environment, the artificial environment and human environment. Specific, refined environment created in the image can create an elegant, romantic atmosphere of the city, more conducive to urban planning, regional economic development, and cultural systems and promotion of cultural heritage of the city. On the other hand, the efficiency of research through the city-oriented identification systems and image design of public facilities and improve residents and migrants working, living and transport, reduce operating costs and logistics flow of the city, creating non-trade for the whole city the indirect economic benefits.

\subsection{Urban Color Design}

The use of color to rebuild the urban environment and human contact, simple shapes and bold color logo can help people find out their location and orientation. Color design of the city should be divided into two levels, the first level is the overall color of the city, mainly by building. Beijing Municipal Administration Commission as prescribed in gray color is the Beijing-based composite flag colors. The color is in Beijing 800 years of history in the formation of capital, and Beijing and the geographical and climatic characteristics which are appropriate. Many foreign cities have color 
planning such as Paris logo color is beige; flag color khaki London is like. The second level is related to the urban landscape and people of color, mainly by walkways and squares, all kinds of billboards and urban facilities marked with color, two different levels of action face color, color design reflects the city's diversity and unity of the dialectical relationship.

Color design can also be introduced into the city zoning concept, different areas of the city are available in different colors for the logo, the logo colors partition should conform to the urban fabric, to create colorful urban pattern. As New York City bus station logo design on the use of the color code system: the blue line is where green is the express train, express train senior purple, this color identification system with clear, easy to read and shows the location of the bus system to the passenger line.

\section{Urban CIS is designed to shape the urban cultural characteristics play a key role}

\subsection{City Cultural Image positioning and concept extraction}

Cities CIS during the operation must first carefully handle the city image positioning, and the feasibility study. City image positioning that is extracting the main points from the city and conceptualization natural, cultural, economic and other complex objects. These points can be integrated and concepts should reflect the regional, cultural, characteristics of the times of the city. Regional characteristics mainly reflects urban geographical features, and other local characteristics; cultural city is a comprehensive variety of factors political, economic, religious, ethnic, science, history, heritage, folklore, etc; the times is the inevitable requirement of urban development, complements the geographical and cultural characteristics of spatial sense, to express the full combination of all three urban context, the concept of time and space reflects the significance of the city, to deduce the urban culture distinct personality. Through these elements organize and extraction, urban CIS trying to create a unified whole city, which is the urban planning and design of one of the objectives to be achieved.

\subsection{CIS design elements of the urban landscape}

(1) CIS design and architectural sketches of urban public facilities

Architectural sketches include flower beds, chairs, fences, railings, kiosks, small kiosks, fountains, billboards, etc; urban public facilities including telephone booths, bus stops, pedestrian bridges, trash cans, mailboxes, signs and poles and other instructions. Architectural sketches and urban public facilities are mainly part of the urban culture, current architectural sketches in various cities and a wide range of urban public facilities, the impact was large and complex ownership units, lack of unified planning control. CIS requires that the city will be unified design, unified implementation of unified management. These elements will constitute an important part of the city CIS design. The design and layout should be based on the concept of city CIS extraction, concept analysis to the principle of city CIS logo design as the basis, combined with urban culture reflects the overall planning and unified deployment.

(2) City signs and billboards

Signs of the city there are signs, identification and other units; ads commercials and PSAs points. Urban CIS requires that all signs, logo design should have the characteristics of CIS. It is noteworthy that in the city itself, complete with visual traffic signs, and unity, already have various attributes cities CIS, we deal with its color and image respected.

(3) Greening

Urban greening CIS role mainly in the following aspects: first of many cities were identified by City tree and flower. City tree and floral emblem may be designated geographical features of the city, but also implies a certain humanistic significance. Second, the backbone of the road layout and the choice of species also need overall planning of urban CIS. Third, the breath of flowers and trees to the city can play a marked role, not only the city's rich cultural seasons, and increased interest of the city.

(4) Lighting

City lighting expanded the scope of urban space is an extension of the urban landscape expression. Urban CIS requirements of urban lighting in a unified whole based on lighting partition through 
different lighting colors to express the level of urban space and depth; and based on lighting partition of grading highlights the importance of the place Lighting important distinction according to classification. Lighting Factors city after city CIS collate night should reach so rich layers of urban space and focused purposes. Lighting can be based on the partition of urban structure with different colors to express; lighting classifying use more ways, such as halos, light color, light intensity changes, the use of sports lighting (laser light), etc., to the city overall culture coincide, can not superfluous.

\section{Summary}

Content cities CIS involved in basic urban planning, urban design are covered, but these are dispersed in urban planning, urban design among the professional, did not get a unified plan. In the information society, the wealth of the constitution, the knowledge represented by the proportion of intangible assets will grow; on the city in terms of value to the image and information as the representative value of intangible assets is also an important component constituted section. No image of the city, fuzzy image of the city, it is difficult in the rapid development of the information society.

Injection in urban construction image strategy, in terms of the inner city is to enhance the concept of urban development, clear career field, establishing the goal of building, strengthening cohesion and the excitation force management efforts and cities; urban Externally lies ready multi-communication, strengthen information dissemination, reliability and visibility at home and abroad to expand and society, promote urban construction and development, good urban ecological environment. However, injection CIS image strategy can not be achieved overnight success, urban image design implement long-term, carefully implemented, think big, start small, patiently for harvest.

\section{Acknowledgement}

This research was financially supported by the Students' Innovative Project Financing 2016 "souvenirs Wang Guilin City-based development architecture." ; This study is also the 2016 outcome of a strong base in Guangxi region of excellence projects.

\section{References}

[1] Chen $\mathrm{Xu}$, on the cultural connotation of urban construction [J], Kunming University of Science, 2004.6

[2] Li Changchun, city guide and Recognition System [J], decoration 108

[3] high-Chi, CI- corporate image-building [M], Shenyang: Heilongjiang Fine Arts Publishing House, 1994

[4] (US) • Dai Bole • Gail Fink, city logo design [M], Dalian: Dalian University of Technology Press, 2001

[5] Chen xu. Analysis of the psychology factors in the product form design[J]. Machine Design, 2013, 281, 105-106.

[6] Information on http://www.dolcn.com 